\title{
Beyond Teaching Language: Towards Terminological Primacy in Learners' Geometric Conceptualisation
}

\author{
Humphrey Uyouyo Atebe \& Marc Schäfer \\ Education Department \\ Rhodes University \\ humphrey.atebe@wits.ac.za \& m.schafer@ru.ac.za
}

\begin{abstract}
This paper reports on a specific aspect of a broader geometry conceptualisation study that sought to explore and explicate learners' knowledge of basic geometric terminology in selected Nigerian and South African high schools. It is framed by the notion that students' acquisition of the correct terminology in school geometry is important for their success in the subject. The original study further aimed to determine the relationship that might exist between a learner's ability in verbal geometry terminology tasks and his/her ability in visual geometry terminology tasks. A total of 144 learners (72 each from South Africa and Nigeria) were selected for the study, using both the stratified and the fish-bowl sampling techniques. A questionnaire consisting of a sixty-item multiple-choice objective test provided the data for the study. An overall percentage mean score of $44,17 \%$ obtained in the test indicated that learners in this study had only a limited knowledge of basic geometric terminology. The Nigerian subsample in the study had a weaker understanding of basic geometric terminology than their South African counterparts. Importantly, there were high positive correlations between participants' ability in verbal geometry terminology tasks and their ability in visual geometry terminology tasks. These results are consistent with those of several earlier studies, and provide a reasonably firm basis for certain recommendations to be made.
\end{abstract}

Language is undoubtedly an essential tool in communication, and perhaps geometry stresses the use of language more than any other part of a mathematics curriculum (Ashfield \& Prestage, 2006; Hoffer, 1981). Research on language, particularly, in Africa where most formal education is conducted in a teaching language (such as English or French) usually alien to learners and teachers, has over the years focussed on learners' difficulties with the teaching language and the need to make them proficient in it (Oyoo, 2009). The assumption here, at least in the main, is that once learners have attained an acceptable level of proficiency in the teaching language (semantic understanding), then their understanding of the subject matter (conceptual/mathematical understanding) will naturally follow.

A critical analysis of findings from studies on the educative efficacy of teaching languages, however, indicates that learners who have achieved a commendable level of "proficiency in the language of teaching have often been found unable to follow classroom discussions [even] with 'good' teachers" of the subject (Von Glaserfield, as cited in Oyoo, 2009, p. 197). The problem of comprehension tends to arise when both the learner and the teacher know the meaning of a word at a basic semantic level and therefore assumes that the word's technical or conceptual meaning is equally shared. This suggests that during teaching, the teacher uses certain words in a sense peculiar to the subject that is not precisely understood by the learners. While learners' proficiency in the teaching language is important for social interaction in the classroom, learning mathematics generally, and geometry specifically, involves more 
than just social interaction in the classroom. Learners need to acquire the correct technical terms and be able to use them clearly to communicate their ideas about concepts in geometry. Premised upon this statement, the present study was undertaken to explore learners' knowledge of basic terminology in plane geometry in selected Nigerian and South African high schools. The authors acknowledge that language proficiency amongst learners cannot be assumed to be constant within schools and across schools. Nevertheless, for the purposes of this paper we assumed a common basic level of proficiency in English, the language of teaching in the participating schools.

\section{Rationale and significance}

The point that has been stressed by the South African National Curriculum Statement concerns the need to promote learners' "competence in mathematical process skills such as investigating, generalising and proving" (Department of Education, 2003, p. 9), a competence vital for their overall mastery of mathematics. An emerging argument from research is that learners' ability to classify geometrical objects in terms of their properties facilitates their acquisition of these mathematical process skills (Roberts, 2010), and few would argue that knowledge of the correct technical language plays an important role in the classification process.

As indicated, this study is underpinned by the notion that students' acquisition of the correct terminology in school geometry is important for their success in the subject. Although it has long been recognised that "the most basic type of knowledge in any particular field is its terminology" (Bloom, 1956, p. 63), it is only recently that this notion has begun to attract empirical attention in geometry education. Recent research has indicated that a lack of language competency impedes progress in geometric understanding (Feza \& Webb, 2005). De Villiers (as cited in Feza \& Webb, 2005, p. 45), for example, stresses the point that "success in geometry [indeed] involves acquisition of the technical terminology". All too often, however, students lack the appropriate vocabulary to express the distinguishing properties of a figure or compare shapes in an orderly manner (Renne, 2004). The learners' repertoire of geometric terminology that we explore in this study is not synonymous with and does not replicate that investigated in any earlier studies: it draws upon their findings but breaks new ground in the field of enquiry.

Students' difficulty with, and misconceptions in geometry can, in part, be linked to their "lack of exposure to proper [geometric] vocabulary" (Oberdof \& Taylor-Cox, 1999, p. 340) in the subject (Mji \& Makgato, 2006). It is thus hoped that this study may be able to indicate to teachers in Nigeria and South Africa (and elsewhere) possible reasons for the misunderstandings and difficulties that plague discussions of geometry in the classroom. Insight of this nature is important for remedial teaching design and delivery. Furthermore, the determination and subsequent analysis of the correlations between a student's ability in verbal geometry terminology tasks and his/her ability in visual geometry terminology tasks, as exemplified by students' scores in the test instrument used in this study, are of particular significance to both prospective and practising teachers. While it is important to teach the terminology associated with a given content area in geometry, it is equally important for teachers to ensure that a learner who can give a correct verbal description of a geometric concept also has the correct concept image associated with that concept, and vice versa. This is vital to assessment of learners' conceptual understanding in this learning area (Hiebert \& Lefevre, 1986).

This paper reports on a specific aspect of a broader study (Atebe, 2008), and extends a previous preliminary report (Atebe \& Schafer, 2010) by offering much richer data, in particular a concept-byconcept analysis of learners' performance, grade-level analysis and interpretations. For more detail concerning the current study and its significance, refer to Atebe (2008).

\section{Theory and related research}

In 1957, a husband-and-wife team of Dutch mathematics educators, Pierre van Hiele and Dina van HieleGeldof, completed companion doctoral dissertations at the University of Utrecht that focussed on the difficulties that school children experience in geometry and how they can best be assisted through teaching. The van Hieles asserted that students pass through several levels of reasoning in their development of geometric ideas (Clements, 2004; Pegg, 1995). They developed a theory of levels of 
thought in geometry, now known as the van Hiele theory, which suggests that students pass through a sequence of five hierarchical levels of geometric thinking as they progress from merely recognising geometric shapes to being able to construct a formal geometric proof (Atebe \& Schafer, 2008; Clements, 2004; Teppo, 1991; van Hiele, 1986, 1999). The theory also offers a model of teaching to promote learners' levels of understanding in geometry (Fuys, Geddes, \& Tischler, 1988; van Hiele, 1986). This implies that there are at least two aspects to the van Hiele theory: the thought levels and the learning phases. The van Hiele levels are: recognition, description, ordering, deduction and rigour (see Hoffer, 1981 for details), while the van Hiele learning phases are: information, guided orientation, explicitation, free orientation, and integration (see Atebe, 2008 for details).

Various aspects of the van Hiele theory have been explored in previous publications. For example, Usiskin (1982) and Atebe (2008) offer comprehensive reports on the van Hiele theory as a whole; Atebe and Schafer (2008) explicate the thought levels in some detail, and Atebe and Schafer (2009) focus in depth on the teaching phases of the van Hiele theory. In this paper, therefore, relatively cursory treatment is accorded the van Hiele thought levels and learning phases. Nevertheless, since the properties of the van Hiele levels - the very aspect of the van Hiele theory with reference to which the results of this study were analysed and interpreted - have hitherto received little scholarly attention, they remain the main focus of this literature review.

\section{Properties of the van Hiele levels}

The van Hieles made certain observations about the nature of the levels of thinking in geometry and their relationship with geometry classroom teaching. In order to understand how an individual student progresses from one van Hiele level to the next, early van Hiele researchers like Usiskin (1982), Fuys et al. (1988) and of course, the van Hieles themselves, identified the following properties as pertaining to the levels: 1) fixed sequence/hierarchy, 2) linguistic character, 3) adjacency, 4) discontinuity, 5) retention and 6) ascendancy/progress. Only property 2 - the linguistic character of the van Hiele levels - is elaborated on in this paper (see Usiskin, 1982; Atebe, 2008 for discussion of the others).

\section{Linguistic character of the van Hiele levels}

An important consequence of the van Hiele theory is its pedagogical relevance to teaching in geometry. Each of the levels is characterised by its own linguistic symbols, terminology and network of relations. People reasoning at different levels speak different languages and the same term is interpreted differently. In a classroom situation, for example, one might find the teacher, the texts, and the students functioning at different levels and hence using different linguistic symbols or networks of relations. Consequently, the students and the teacher do not understand each other (Mason, 1998; van Hiele, 1986). The mismatch between teaching and students' cognitive levels in geometry is caused largely by teachers' failure to deliver teaching to the pupils in a language that is terminologically appropriate to the students' thinking levels (Oyoo, 2009; van Hiele, 1986). Van Hiele (1986) sees this property as the most critical in the learning process:

In education, teachers often give their students unsolvable problems. They use the language of the third level and the pupils often are not even able to use the language of the second level. Sometimes the pupils have not even formed a language of the first level that accompanies the visual structure. (p. 90)

The result of such teaching is that the learners are obliged to imitate, but without understanding, the action structure of the teacher. Van Hiele (1986) therefore proposes that "a teacher beginning the teaching of geometry should address himself to the pupils in a language they understand" (p. 45). By this van Hiele means that teachers should use level-appropriate terminology, symbols, and general language in their geometry teaching practices. In line with this view, the third of the van Hiele learning phase descriptors as formulated by Atebe $(2008$, pp. 72, 286) recommends that "teachers [should] ask questions that seek to clarify [their] students' imprecise terminology and gradually introduce formal mathematical terms". Hoffer (1981, p. 12) similarly suggests that precise terminology should "be thrust on students" early in their geometry course in order to remediate their use of imprecise geometric terminology, which is often attributable to misconceptions that they hold. 
Given the foregoing theoretical perspectives on geometric terminology and students' acquisition of geometric ideas, the determination of the repertoire of geometric terminology at the disposal of high school learners (in Nigeria and South Africa) for possible remedial teaching design and delivery cannot be taken for granted. The teaching of basic geometric terminology should be given pride of place in the teaching of high school geometry.

\section{The research goals}

This study sought to explore and explicate high school learners' knowledge of basic technical terms in geometry in selected Nigerian and South African schools. The study further sought to determine what relationship might exist between a learner's ability in verbal geometry terminology tasks and his/her ability in visual geometry terminology tasks.

\section{Method}

The research design is that of a collective case study (Stake, 2000), focusing on a total of 144 mathematics learners drawn from two high schools in Nigeria and South Africa - one school from each country. As a research approach, a case study typically investigates the "particularity and uniqueness of a single case, coming to understand its activity within important circumstances" (Stake, 1995, p. xi). However, Stenhouse (as cited in Schäfer, 2003, p. 49) points out that in the case of "educational case studies", collective case study approaches - such as that employed in this study - are increasingly being used.

\section{The sample and sampling procedures}

The sample comprised a total of 144 Nigerian and South African high school learners with a mean age of 16,6 years. Of the 144 learners, 72 were drawn from a state-owned high school in Ojo Local Education District in Lagos State, Nigeria, and the other 72 from a 'township' high school in Makana Educational District in Eastern Cape Province, South Africa. In each of these schools, 24 learners from each of Grades 10,11 and 12 were selected for the study using stratified and fish-bowl sampling techniques.

Given the limitation of involving only one school from each of the participating countries, the choice of which schools to study was a critical factor. Although geographical accessibility and proximity, functionality, and gender composition (single-gender or co-educational) were some of the important factors that influenced our choice of school, the primary criterion was their easy accessibility to the majority of Nigerian and South African learners because of the relatively low cost of attending them. For more comprehensive information concerning the sample and the sampling procedures, see Atebe (2008).

\section{Collection of data}

Data were collected for this study mainly through the construction and administration of a structured questionnaire which was issued to the learners in the form of a pen-and-paper test. The questionnaire consisted of a sixty-item multiple-choice objective test referred to as the Terminology in Plane Geometry Test (TPGT). Each question was followed by a list of four options (or foils) from which the learners were expected to choose the correct answer. Choppin (1988, p. 354) asserts that the objective test, as a means of data collection in educational research, is structured in such a way that "the testees must choose their answers from a specific list of alternatives rather than creating them for themselves". Anderson (1990) similarly states that distinct choices in a questionnaire eliminate possible ambiguity in the responses of the research participants and facilitate a very precise form of data analysis.

For the TPGT, two conceptually identical but structurally different sets of questions were constructed for each terminology. That is, for every question that was presented in a verbal form (i.e. without diagrams), there was a corresponding one presented in a visual form (i.e. presented diagrammatically). All the items in the test were then juggled, so that each member of every homologous (i.e. identical) pair of questions 
was separated from the other. Hence, the TPGT consisted of 30 verbally represented questions (the oddnumbered items) and a corresponding 30 visually represented ones (the even-numbered items). In line with the goal of this study, the purpose of the homologous pair of questions in this test was to determine whether a student who can give a correct verbal description of a geometric concept also has the correct visual (or conceptual) image associated with the concept, and vice versa. Questions 5 and 24, reproduced below, exemplify a pair of homologous questions used in the TPGT.

Question 5: What is the name of the chord that passes through the centre of a circle?
A. A tangent
B. A radius
C. An arc
D. A diameter

Its visual image homologous pair (or counterpart) is:

Question 24: In the diagram, $O$ is the centre of the circle. Which of the following is a diameter?

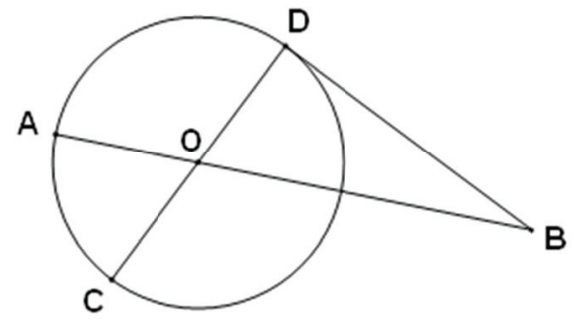
A. AOB
B. DB
C. $\mathrm{COD}$
D. $\mathrm{OB}$

For the TPGT, a total of 30 terms pertaining to three different but interrelated concepts in plane geometry were examined. The concepts to which these terms relate are: 1) circles, 2) triangles and quadrilaterals, and 3) lines and angles. Figure 1 presents the terminology examined.

\begin{tabular}{|lll|}
\hline Circle & Triangles and quadrilaterals & Lines and angles \\
Radius & Equilateral triangle & Acute angle \\
Chord & Isosceles triangle & Right angle \\
Diameter & Scalene triangle & Obtuse angle \\
Tangent & Right-angled triangle & Reflex angle \\
Arc & Similar triangle & Alternate angles \\
Sector & Altitude of a triangle & Vertically opposite angles \\
Cyclic quadrilateral & Area of a right-angled triangle & Complementary angles \\
Concentric circles & Number of sides in a triangle & Supplementary angles \\
& Number of sides in a quad. & Corresponding angles \\
& Diagonals of a quadrilateral & Parallel lines \\
& Lines of symmetry & Perpendicular lines \\
& & \\
\hline
\end{tabular}

Figure 1: Concepts and their associated terminology in the TPGT 


\section{Administration and grading of the TPGT}

We personally administered the TPGT to all 144 learners (three learners were absent in Nigeria on the day of this test, though), with the assistance of the mathematics teachers from the participating schools. With regard to test grading, scoring of students' responses was done using ScanTools for Windows version 2.2. The percentage score was calculated for each student and an item analysis of students' responses was done using Microsoft Excel (see Atebe, 2008 for details).

\section{Results and discussion}

Information about students' knowledge of basic geometric terminology is acquired through analysis and interpretation of participants' performance in the TPGT.

\section{Overall participants' performance in the TPGT}

Students' general performance in the TPGT was described in terms of the overall participants' percentage mean score obtained in this test. Table 1 summarises participants' performance in the TPGT.

Table 1: Percentage mean score of all participants in the TPGT

\begin{tabular}{cccccc}
\hline School & $\boldsymbol{N}$ & Mean score & Std deviation & Min score & Max score \\
\hline NS & 69 & 40,49 & 16,78 & 17 & 90 \\
SAS & 72 & 47,85 & 13,82 & 27 & 87 \\
\hline
\end{tabular}

Note: $\mathrm{NS}=$ Nigerian subsample; $\mathrm{SAS}=$ South African subsample

As is evident from Table 1, the percentage average score obtained by learners from the Nigerian subsample in the TPGT was 40,49\%, and that of the learners from the South African subsample, 47,85\%. A simple calculation from Table 1 indicates that the percentage mean score obtained by all the participating learners in the TPGT was $44,17 \%$. Given that the items that made up the TPGT were largely van Hiele level 1 in nature, and that the TPGT as a whole was a straightforward test of learners' knowledge of the simplest and most common geometric terminology frequently encountered in junior and high school geometry, this rather low percentage mean score is an indication that this cohort of high school learners had a low level of terminology knowledge in this learning area. That is, learners in this study had a weak understanding of basic terminology associated with high school geometry.

\section{Performance of Nigerian and South African learners in the TPGT}

The mean score of learners from Nigeria was compared with that of learners from South Africa. The aim was to determine how Nigerian high school children compare with their South African peers in the TPGT (see Atebe, 2008 for the basis for this comparison). The results are summarised in Table 2.

Table 2: School percentage means for learners in the TPGT

\begin{tabular}{ccccccc}
\hline School & $\boldsymbol{N}$ & Mean score & SD & $\boldsymbol{t}$-value & $\boldsymbol{d} \boldsymbol{f}$ & $\boldsymbol{p}$-value \\
\hline NS & 69 & 40,49 & 16,78 & $-2,85$ & 139 & $0,0051^{*}$ \\
SAS & 72 & 47,85 & 13,82 & & & \\
\hline
\end{tabular}

Note $:$ NS $=$ Nigerian subsample; $\mathrm{SAS}=$ South African subsample

${ }^{*} p<0,05$

Table 2 indicates that the mean score of the South African learners on the TPGT was higher than the mean score obtained by the Nigerian learners. A test of significance revealed that the difference between 
the means of the Nigerian and the South African learners in the TPGT was significant in favour of the South African learners. What this result shows is that, on average, participants from South Africa performed significantly better than their Nigerian peers in the TPGT; or in other words, that the Nigerian subsample in this study had a somewhat weaker understanding of basic geometric terminology than its South African counterpart.

\section{Grade level performance in the TPGT}

Grade level analysis of learners' performance in the TPGT focused on the relative performance of Grade 10, 11 and 12 learners in the Nigerian and South African subsamples. These results are represented on Figure 2.

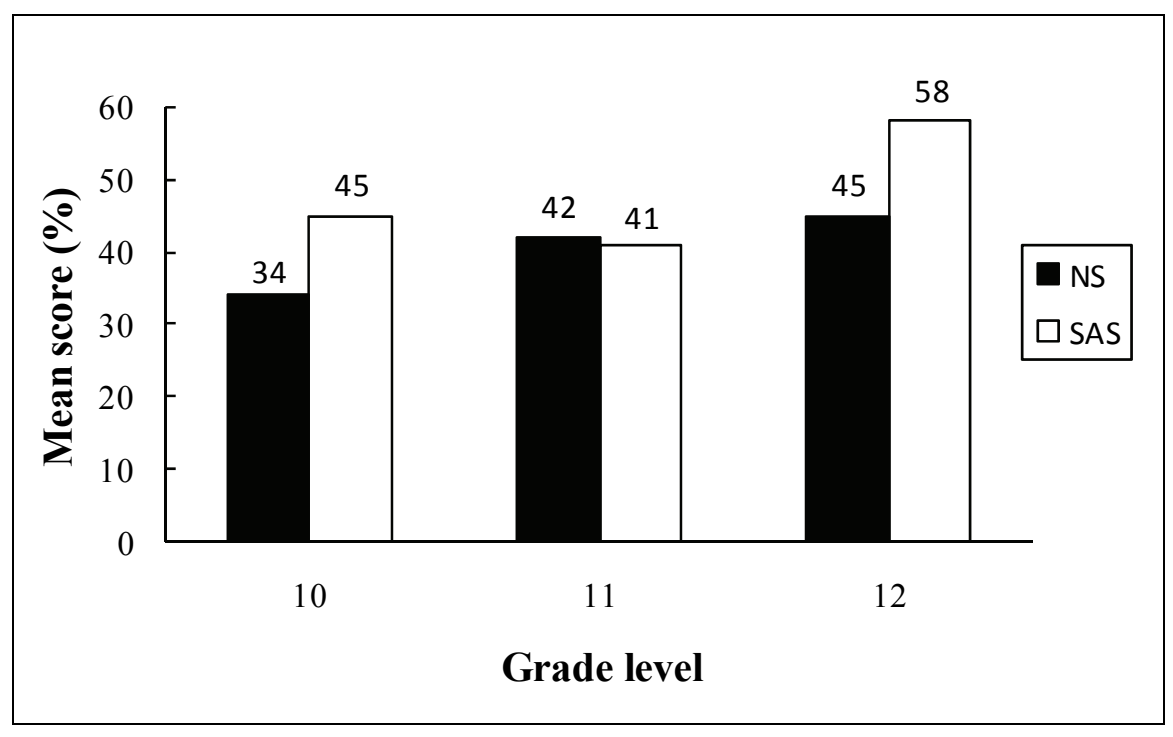

Figure 2: Grade level performance of learners in the TPGT

Figure 2 reveals a marginal progressive increase in performance along the grade levels for the Nigerian subsample. For the Nigerian participants, the percentage mean score (45\%) obtained by Grade 12 learners was marginally higher than that of Grade 11 learners $(42 \%)$, which was in turn marginally higher than the mean score of the Grade 10 learners. Given these little differences in the mean scores of learners from across Grades 10-12 of the Nigerian subsample, it could be hypothesised that the Nigerian high school learners in this study add only a little to their repertoire of geometric terminology as they progress from Grade 10 through 12 .

An interesting revelation in Figure 2 about the grade level performance of South African participants is that the Grade 10 learners outperformed the Grade 11 learners in the TPGT. As the Figure illustrates, the mean score (45\%) of South African Grade 10 learners was marginally greater than the mean score (41\%) obtained by Grade 11 learners. South African Grade 12 learners, however, obtained a higher mean score (58\%) than both Grade 10 and 11 learners. What these results show is that the South African Grade 11 learners involved in this study had a weaker understanding of basic geometric terminology than their peers in Grades 10 and 12. That Grade 10 learners from the South African subsample outperformed their Grade 11 peers in the TPGT turned out not to be by chance, since for all other tests used in the larger study (Atebe, 2008), the Grade 10 South African learners consistently obtained higher mean scores than the Grade 11 learners. Why this should have been so was not investigated in the current study.

The grade level analysis of learners' performance in the TPGT further indicated that South African learners, with the exception of Grade 11, obtained higher mean scores than their Nigerian peers. In fact, the Nigerian Grade 12 learners obtained a mean score (45\%) equal to that of the South African Grade 10 learners. In Grade 11, the mean score of the Nigerian learners (42\%) was marginally greater than that of their South African counterparts, which was $41 \%$. 


\section{Grade level comparison of mean scores in the TPGT}

Further analysis was done to determine whether or not the differences in the mean scores of the Nigerian and the South African participants in the TPGT reported in the preceding section at each grade level were significant. The results, which are represented in Table 3, indicated the following: There was a statistically significant difference in the mean score of Nigerian Grade 10 learners and South African Grade 10 learners in favour of the latter. That is, South African Grade 10 learners performed significantly better than their Nigerian peers on the TPGT. The test of significance also revealed that although Nigerian Grade 11 learners obtained a marginally higher mean score on the TPGT than their South African counterparts, the difference in the mean scores of these two groups was not statistically significant. This means that Nigerian Grade 11 learners did not achieve significantly better results than their South African Grade 11 counterparts in the TPGT.

Table 3: Grade level mean scores in the TPGT

\begin{tabular}{|c|c|c|c|c|c|c|c|c|c|}
\hline \multirow[t]{2}{*}{ Grade } & \multicolumn{3}{|c|}{ Nigerian subsample } & \multicolumn{3}{|c|}{ South African subsample } & \multirow[t]{2}{*}{$t$-value } & \multirow[t]{2}{*}{$d f$} & \multirow[t]{2}{*}{$p$-value } \\
\hline & $N$ & Mean & $\mathrm{SD}$ & $N$ & Mean & $\mathrm{SD}$ & & & \\
\hline 10 & 21 & 33,62 & 10,15 & 24 & 44,63 & 7,22 & $-4,23$ & 43 & $0,0001 * * *$ \\
\hline 11 & 24 & 41,67 & 19,51 & 24 & 40,50 & 8,16 & 0,27 & 46 & 0,7882 \\
\hline 12 & 24 & 45,33 & 17,13 & 24 & 58,42 & 16,94 & $-2,66$ & 46 & $0,0107 *$ \\
\hline
\end{tabular}

Note: ${ }^{*} p<0,05 ; * * * p<0,001$

The $t$-test further revealed that there was a significant difference between the mean score of Nigerian Grade 12 learners and that of their South African peers in favour of South African learners. That is, South African Grade 12 learners performed significantly better than Nigerian Grade 12 learners in the TPGT. These results further buttress our earlier claim that on average, South African learners involved in this study have a better knowledge of basic geometric terminology than their Nigerian counterparts.

\section{Mean scores in the TPGT of all participants by gender}

As Figure 3 illustrates, this study identified a gender difference in performance in the TPGT in favour of male learners. On average, male learners obtained higher scores, with a mean score of $48 \%$, than female learners, who obtained a mean score of $41 \%$.

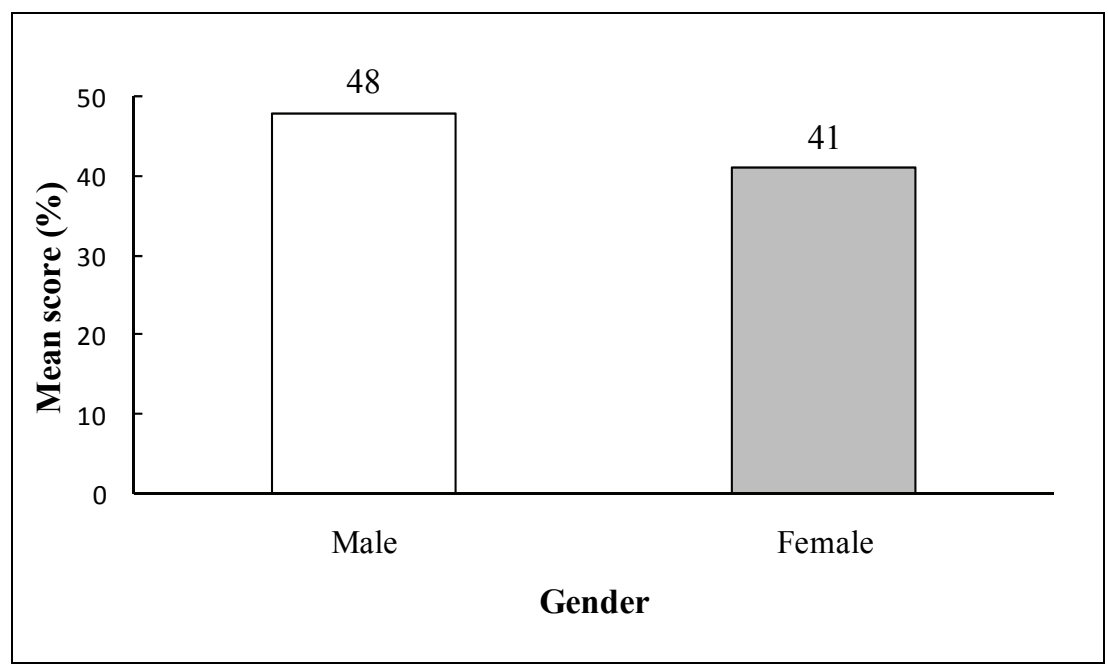

Figure 3: Gender difference in mean scores in TPGT

A test of significance conducted indicated that the difference between the male and female mean scores was statistically significant, as shown in Table 4. 
Table 4: Mean scores in the TPGT by gender

\begin{tabular}{lcccccc}
\hline Gender & $\boldsymbol{N}$ & Mean score & SD & $\boldsymbol{t}$-value & $\boldsymbol{d} \boldsymbol{f}$ & $\boldsymbol{p}$-value \\
\hline Male & 68 & 48,04 & 16,49 & $-2,84$ & 139 & $0,0053^{* *}$ \\
Female & 73 & 40,71 & 14,19 & & & \\
\hline
\end{tabular}

Note: $* * p<0,01$

These results were consistent with those of Usiskin's (1982, p. 84) study, in which he reported that in the comparative and similar Entering Geometry Test, the mean score of American high school male learners was significantly greater than that of their female counterparts. The results were also consistent with those of Barnard and Cronjé's (1996, p. 1) study in which "differential gender performance was in favour of most males" in South Africa in a 20-item multiple-choice Euclidean geometry test. See Atebe (2008) for gender differences determined for each of the participating schools.

\section{Mean scores of all participants in the TPGT by concept}

For the analysis in this section, students' mean scores in the TPGT were calculated separately for items on geometric terminology associated with the concepts of circles, triangles and quadrilaterals, and lines and angles. The results are as shown on Figure 4.

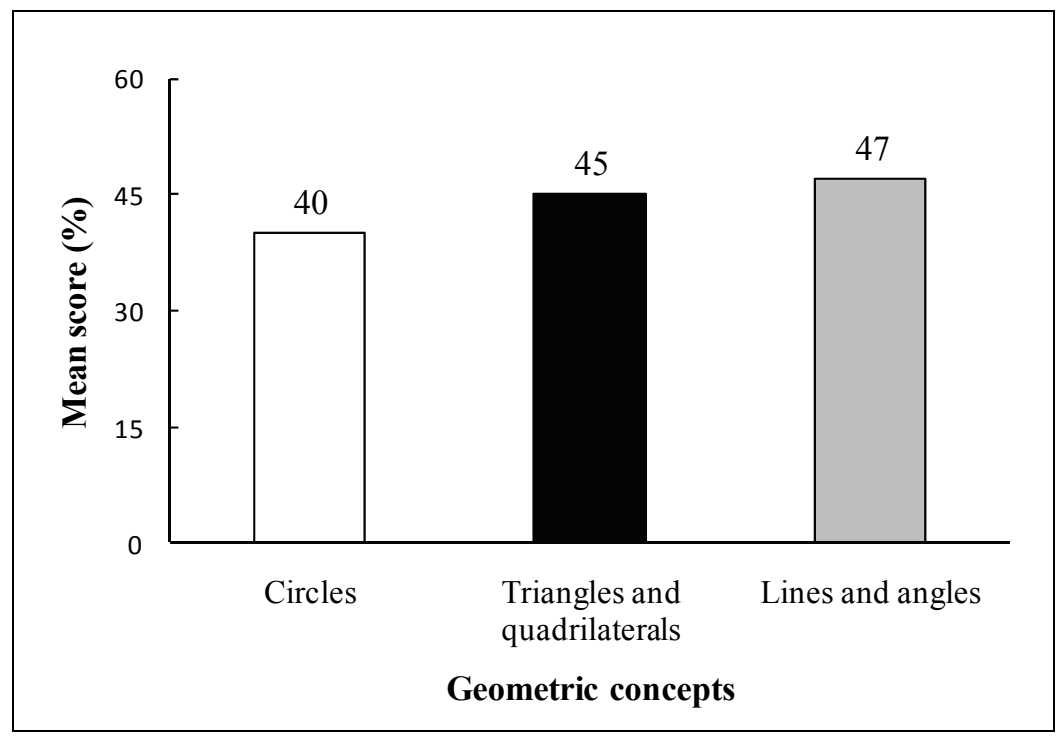

Figure 4: Mean scores of learners in the TPGT by concept

As Figure 4 illustrates, the learners participating in this study showed a rather weak knowledge of geometric terminology across all three geometric concepts according to which items in the TPGT were drawn up. In relative terms, however, these learners demonstrated a better knowledge of terms in geometry associated with the concept of lines and angles than those associated with circles, or with triangles and quadrilaterals. The higher mean score of $47 \%$ indicated that these learners were more comfortable when dealing with geometric terminology associated with lines and angles than that associated with the concepts of circles, and triangles and quadrilaterals, for which they obtained mean scores of $40 \%$ and $45 \%$, respectively. These results were found to be partly consistent with those of Kouba, Brown, Carpenter, Lindquist, Silver and Swafford (as cited in Clements \& Battista, 1992, p. 421), who reported that in America, "students' performance at identifying common geometric figures, such as parallel lines... [was] acceptable", but that students' knowledge of some basic geometric terms associated with the concept of the circle was deficient. 


\section{Correlation between verbal and visual abilities of learners in the TPGT}

The correlation between students' ability in verbal and visual geometry terminology tasks was determined. By correlating students' scores from the verbally presented items in the TPGT, correlation coefficients were obtained separately for the Nigerian and South African subsamples. Both correlations were found to be significant, as indicated in Table 5.

Table 5: Correlation coefficients for the TPGT by school

\begin{tabular}{lccccccc}
\hline School & \multicolumn{2}{c}{ Verbally presented items } & \multicolumn{2}{c}{ Visually presented items } & $\boldsymbol{N}$ & $\boldsymbol{r}$-value & $\boldsymbol{p}$-value \\
& Mean & SD & Mean & SD & & & \\
\hline NS & 11,16 & 5,12 & 13,13 & 5,45 & 69 & 0,83 & $0,00001^{* * *}$ \\
SAS & 12,68 & 4,61 & 15,99 & 4,58 & 72 & 0,63 & $0,00001^{* * *}$ \\
\hline
\end{tabular}

Note: $\mathrm{NS}=$ Nigerian subsample, $\mathrm{SAS}=$ South African subsample

$* * * p<0,001$

As is evident in Table 5, the values of the correlation coefficients calculated for both the Nigerian and South African subsamples are positive. This means that a student who correctly answered a verbally presented question in the TPGT also answered its visually presented identical counterpart correctly, and vice versa. That the values of the coefficients are fairly large does not necessarily indicate that the learners have an impressive grasp of geometric terminology. The coefficients only give information about the level of consistency with which participants responded to homologous pairs of questions in the TPGT.

The correlation coefficient calculated for the Nigerian subsample $(0,83)$ was greater than that calculated for the South African subsample $(0,63)$. This again does not imply superiority in performance on the part of the Nigerian subsample over that of the South African. What it does mean is that Nigerian learners were more consistent in their responses to the items in the TPGT than their South African peers. That is, more Nigerians passed or failed identical pairs of questions in the TPGT than South Africans. The higher mean score obtained by the South African subsample in the TPGT (reported earlier) compared with that of the Nigerian participants supports this disclaimer.

Even with the interpretation given in the preceding paragraph, there could be many other dimensions to what these correlation coefficients tell us about students' conceptual understanding of geometric terminology. That the correlation coefficient for the Nigerian subsample was greater than that of the South African participants means that more Nigerian learners than South Africans who knew the correct verbal description of a geometric concept also had the correct visual/concept image associated with the concept. In terms of the conceptual understanding of basic terminology in geometry, this would mean that South African participants were less conceptually grounded than their Nigerian peers; it could be that the SAS learners engaged in random guessing that resulted in the correlation coefficient being lower than that of the Nigerian participants.

Another interpretation, and perhaps one more tenable, is that South African learners had a more comprehensive understanding of basic geometric terminology than their Nigerian counterparts and hence obtained a higher mean score in the TPGT. But this understanding is less conceptual, as the SAS learners tended to understand the terminology better only in one form of presentation, namely the visual form. Simple calculations from Table 5 reveal that there is a wider difference between the mean scores of South African learners for the verbally presented items and the visually presented items than there is for learners from the Nigerian subsample. This indicates that the South African learners were less successful with geometry terminology tasks that were presented in verbal form than the Nigerian participants.

To conclude, Table 5 further indicates that learners from both the Nigerian and the South African subsamples had a better understanding of geometric terminology presented in terms of visual tasks than those that were presented in verbal form, and hence obtained higher mean scores in the former than in the latter. 


\section{Conclusion}

This study has investigated learners' knowledge of basic geometric terminology in selected Nigerian and South African high schools. The motivation was the theoretical standpoint that students' acquisition of the correct terminology is important for their success in the subject (van Hiele, 1986).

Analysis of participants' responses to the TPGT showed that learners in this study had a limited and arguably inadequate knowledge of basic geometric terminology, since they were only able to obtain an overall percentage mean score of $44,17 \%$ in this test even when the TPGT dealt with the simplest of geometry facts and concepts. Learners from the South African subsample performed significantly better than their Nigerian peers in the TPGT: There was a statistically significant difference between the mean score of South African learners (47,85\%) and that of the Nigerian subsample $(40,49 \%)$ in favour of the former. Given the lower mean score, learners from the Nigerian subsample in this study were considered to have a weaker understanding of basic geometric terminology than their South African counterparts.

In this study, differential gender performance was in favour of the male learners in respect of the basic geometric terminology test.

There were high positive correlations between participants' ability in verbal geometry terminology tasks and their ability in visual geometry terminology tasks. For the participants in this study, learners who knew the correct verbal description of a geometric concept also had the correct visual image associated with the concept, and vice versa. Learners' mean score for the visual geometry terminology tasks was, however, greater than their mean score for the verbal geometry terminology tasks comprising the TPGT. This would mean that learners are more comfortable dealing with visual geometry terminology tasks than verbal geometry terminology tasks.

\section{Recommendation}

Given the results of this study, it is important that the teaching of basic geometric terminology be foregrounded in school mathematics. This could assist the teacher in detecting misconceptions among learners and enable him/her to correct them early in classroom interaction. It is also recommended that teachers make use wherever possible of authentic examples or graphic representations thereof during geometry teaching, since learners tend to have a better understanding of geometry terminology tasks that are presented in visual form than those that are presented in verbal form.

\section{Acknowledgement}

The sponsorship of this research by the FirstRand Foundation Mathematics Education Chair at Rhodes University is hereby acknowledged. Opinions expressed and conclusions arrived at, are those of the authors and are not necessarily to be attributed to Rhodes University or the donor.

\section{References}

Anderson, G. (1990). Fundamentals of educational research. London: Falmer Press.

Ashfield, B., \& Prestage, S. (2006). Analysing geometric tasks considering hinting support and inscriptions. In D. Hewitt (Ed.), Proceedings of the British Society for Research into Learning Mathematics Day Conference 26 (Vol 1, pp. 11-16). London: BSRLM.

Atebe, H. U (2008). Students' van Hiele levels of geometric thought and conception in plane geometry: A collective case study of Nigeria and South Africa. (Unpublished doctoral dissertation). Rhodes University, Grahamstown. Available from http://eprints.ru.ac.za/1505/1/atebe-phd-vol1.pdf

Atebe, H. U., \& Schäfer, M. (2008). Van Hiele levels of geometric thinking of Nigerian and South African mathematics learners. In M. V. Polaki, T. Mokuku, \& T. Nyabanyaba (Eds.), Proceedings of the $16^{\text {th }}$ Annual Conference of the Southern African Association for Research in Mathematics, Science and Technology Education (pp. 104-116). Maseru, Lesotho: SAARMSTE.

Atebe, H. U., \& Schäfer, M. (2009). The face of geometry instruction and learning opportunities in selected Nigerian and South African high schools. In M. Schäfer \& C. McNamara (Eds.), Proceedings of the $17^{\text {th }}$ Annual Conference of the Southern African Association for Research in Mathematics, Science and Technology Education (pp. 7-21). Grahamstown: SAARMSTE. 
Atebe, H. U., \& Schäfer, M. (2010). Terminological primacy in high school learners' geometric conceptualization. In V. Mudaly (Ed.), Proceedings of the $18^{\text {th }}$ Annual Conference of the Southern African Association for Research in Mathematics, Science and Technology Education (Vol. 1, pp. 119-129). Pinetown: SAARMSTE.

Barnard, J. J., \& Cronjé, L. S. (1996). Euclidean geometry: Cognitive gender differences. South African Journal of Education, 16(1), 1-4.

Bloom, B. S. (Ed.). (1956). Taxonomy of educational objectives. Handbook I: The cognitive domain. New York, NY: Longmans, Green.

Choppin, B. H. (1988). Objective test. In J. P. Keeves (Ed.), Educational research, methodology, and measurement: An international handbook (pp. 354-358). New York, NY: Pergamon Press.

Clements, D. H. (2004). Perspective on "The child's thought and geometry". In T. P. Carpenter, J. A. Dossey, \& J. L. Koehler (Eds.), Classics in mathematics education research (pp. 60-66). Reston, VA: National Council of Teachers of Mathematics.

Clements, D. H., \& Battista, M. T. (1992). Geometry and spatial reasoning. In D. A. Grouws (Ed.), Handbook on mathematics teaching and learning (pp. 420-464). New York, NY: Macmillan.

Department of Education. (2003). National curriculum statement Grades 10-12 (General): Mathematics. Pretoria: Department of Education.

Feza, N., \& Webb, P. (2005). Assessment standard, van Hiele levels, and grade seven learners' understandings of geometry. Pythagoras, 62, 36-47.

Fuys, D., Geddes, D., \& Tischler, R. (1988). The van Hiele model of thinking in geometry among adolescents. Journal for Research in Mathematics Education. Monograph, Vol. 3, Reston, VA: National Council of Teachers of Mathematics.

Hiebert, J., \& Lefevre, P. (1986). Conceptual and procedural knowledge in mathematics: An introductory analysis. In J. Hiebert (Ed.), Conceptual and procedural knowledge: The case of mathematics (pp. 1-27). New Jersey, NJ: Lawrence Erlbaum.

Hoffer, A. (1981). Geometry is more than proof. Mathematics Teacher, 74(1), 11-18.

Mason, M. (1998). The van Hiele levels of geometric understanding. In L. McDougal (Ed.), The professional handbook for teachers: Geometry (pp. 4-8). Boston, MA: McDougal-Littell/Houghton-Mifflin.

Mji, A., \& Makgato, M. (2006). Factors associated with high school learners' poor performance: A spotlight on mathematics and physical science. South African Journal of Education, 26(2), 253-266.

Oberdorf, C. D., \& Taylor-Cox, J. (1999). Shape up! Children's misconceptions about geometry. Teaching Children Mathematics, 5(6), 340-346.

Oyoo, S. O. (2009). Beyond general proficiency in language of instruction: Towards the appropriate perspective on language for effective learning in African science classrooms. In M. Schäfer \& C. McNamara (Eds.), Proceedings of the $17^{\text {th }}$ Annual Conference of the Southern African Association for Research in Mathematics, Science and Technology Education (pp. 197-212). Grahamstown: SAARMSTE.

Pegg, J. (1995). Learning and teaching geometry. In L. Grimison \& J. Pegg (Eds.), Teaching secondary school mathematics: Theory into practice (pp. 87-103). London: Harcourt Brace.

Renne, C. G. (2004). Is a rectangle a square? Developing mathematical vocabulary and conceptual understanding. Teaching Children Mathematics, 10(5), 258-264.

Roberts, A. (2010). Language in mathematics classrooms - catalyst or impediment to learning? In V. Mudaly (Ed.), Proceedings of the $18^{\text {th }}$ Annual Conference of the Southern African Association for Research in Mathematics, Science and Technology Education (Vol. 1, pp. 15-24), Pinetown: SAARMSTE.

Schäfer, M. (2003). The impact of learners' spatial capacity and worldviews on their spatial conceptualisation: A case study. (Unpublished doctoral dissertation). Curtin University of Technology, Perth.

Stake, R. E. (1995). The art of case study research. London: SAGE Publications.

Stake, R. E. (2000). Case studies. In N. K. Denzin \& Y. S. Lincoln (Eds.), Handbook of qualitative research (pp. 435-454). London: SAGE Publications.

Teppo, A. (1991). Van Hiele levels of geometric thought revisited. Mathematics Teacher, 84(3), $210-221$.

Usiskin, Z. (1982). Van Hiele levels and achievement in secondary school geometry: Cognitive development and achievement in secondary school geometry project. Chicago, IL: University of Chicago Press.

Van Hiele, P. M. (1986). Structure and insight: A theory of mathematics education. Orlando, FL: Academic Press.

Van Hiele, P. M. (1999). Developing geometric thinking through activities that begin with play. Teaching Children Mathematics, 5(6), 310-317. 